\title{
The Relationship between Intrinsic/Extrinsic Motivation and Medical Students' L2 Writing
}

\author{
Sepideh Nourinezhad \\ Shiraz University of Medical Sciences, Shiraz, Iran \\ Nasrin Shokrpour \\ Shiraz University of Medical Sciences, Shiraz, Iran \\ Zahra Shahsavar \\ Shiraz University of Medical Sciences, Shiraz, Iran
}

\section{Introduction}

Writing skill has an important role in demonstrating the students' learning (Coffin et al., 2003). Although students are evaluated by what they write, writing is generally regarded as a difficult skill and a complex task (Graham, Harris, \& Mason, 2005). Tan (2011) argues that writing is a difficult skill for native and nonnative speakers because writers should balance various issues, such as content, organization, purpose, audience, vocabulary, punctuation, spelling, and mechanics. According to Nunan (2001), writing is a very complex procedure in which a great number of cognitive and meta-cognitive activities take place. Scarcella and Oxford (1992) state that writing in a second language (L2) helps L2 learners to improve their grammatical, strategic, socio-linguistic, and discourse competence in a foreign language. Manchón (2011) claims that L2 writing contributes to second language development; it helps the learners to perceive and understand new linguistic knowledge and improve automatism, knowledge integration and hypothesis testing. It is a facility in which students take power to create meaning as well as share their meaning. As a consequence, writing is more than just transferring one's thought to paper but it helps us to shape and refine our thinking.

One of the most important components that make up a writing task well is the students' motivation (Fazel \& Ahmadi, 2011).Although a lot of research has been conducted in evaluating the students' writing (e.g. Arefi, 1997;Zia Houseini\& Derakhshan, 2006; Kim, 2011; Knoch, 2009; Ayele, 2014), few studies have examined the role of motivation on students' $\mathrm{L}_{2}$ writing development. To fill this 
gap, the present study aimed at investigating the effect of extrinsic and intrinsic motivation on Iranian medical students' L2 writing.

\section{Motivation}

Brown (2001) defines motivation as the intensity of one's impetus to learn. Motivation in the target language influences not only the amount of input learners receive but also the number of L2 learning strategies they use. To this end, motivation has a great impact on the extent to which learners learn a new language and maintain L2 skills after their studies (Oxford\& Shearin, 1994).

There are various taxonomies of motivation. A common categorization of motivation is instrumental and integrative. The former refers to the situation in which the purpose of language learning is to gain a benefit such as getting a job or a higher payment while the latter refers to the situation in which the purpose of language learning is not to get a benefit from learning the language alone, but it is learned to be integrated in its language, culture, and people (Fazel\& Ahmadi, 2011).

On the basis of another classification, motivation is divided into two types: intrinsic and extrinsic. Intrinsic motivation refers to the internal factors and learning of language alone. In contrast, extrinsic motivation is the purpose of getting something as an external factor like getting a prize. To make a relationship between the aforementioned classifications, it could be supposed that intrinsic motivation is related to integrative motivation while extrinsic one is related to instrumental motivation (Hassani, 2005). According to these definitions, the quality of the individual's experience and performance can be different when one is acting for intrinsic versus extrinsic reasons. In this perspective, Ryan and Deci (2000) reexamine the classic distinction between these two types of motivation. They define intrinsic motivation as doing something which is inherently interesting or enjoyable. For example, a student can be highly motivated to do his/her homework out of interest. It means that the student could be motivated to learn a new skill because he or she understands its value. Extrinsic motivation refers to doing something because it leads to a separable outcome. An illustration of this kind of motivation is the student who wants to get a good grade to obtain the consent of teachers or parents. In both examples, the nature and focus of the motivation vary while the amount of motivation is not necessarily different. 


\section{Motivation and learning}

Some researchers investigate the role of motivationin the students' learning. For example, Dörnyei (1998) claims that intrinsic motivation might be negatively connected with different factors such as class anxiety. In contrast, it might be positively related tothe students'educational motivation and self-evaluation of language skills.

In another study, Gardner and Lambert (1972) investigated the effect of integrative and instrumental motivation on L2 learners. The results of their study revealed that students with integrative motivation were more successful in learning than those with instrumental motivation. Contrary to Gardner and Lambert's expectations, Lukmani (1972) argues that although instrumental and integrative motivation are related to the learners' achievement, the former motivation is more highly correlated with the students' achievement in learning English than the latter one.Similarly, Vaezi (2008) claims that Iranian students have very high motivation and positive attitudes towards learning English and they are more instrumentally motivated. The two above-mentioned findings contrast with that of Moiinvaziri (2008) who claims that both integrative and instrumental motivations are related to the students' success in learning.The results of Moiinvaziri's studies are in the same line with those of Gardner and Lambert (1972) who investigated the effect of integrative and instrumental motivation on L2 learners. They found that students with integrative motivation (intrinsic motivation) are more successful in learning than those with instrumental motivation (extrinsic motivation).

According to Lukmani (1972), both instrumental and integrative motivations are related to the learners' achievement; however, the former is more highly correlated with the students' achievement in learning English than the latter one. The probable reason is that motivation to use and learn English has been predominantly driven by extrinsic desires for vocational or socioeconomic advancement (Lin, 1996; Bolton \& Luke, 1999).

\section{Motivation and writing}

Some studies have shown that motivational factors have a great impact on the process and production of difficult tasks such as writing. They claim that the learner's motivation plays a significant role in determining how students will engage in writing activities, what kind of writing tasks they will handle, and how 
much attempt and attention they will run through various phases of their writing process (Bruning \& Horn, 2000).Kormos and Dörnyei (2004) refer to the task of motivation as a crucial factor that can affect the students' L2 writing. Another study shows that students with integrative motivation were more successful in writing as compared with those with instrumental motivation (Fazel \& Ahmadi, 2011).

Although many studies have been conducted on improving the students' writing ability (e.g. Kim, 2011; Knoch, 2009; Ayele, 2014), to the best of our knowledge, the research on the relationship between the students' motivation and their L2 writing is scanty.Moreover, paradoxical results have been shown in the relationship between the students'motivation and their L2 writing. These are the main reasons that promptedus to conduct a research in this area. The current studyis an attempt to investigatethe relationship between intrinsic/extrinsicmotivation and medical students' L2 writing. To do this, the following research questions were posed:

1. Is there a significant difference between the students' L2 writing scores and their motivation?

2. Is there a significant relationship between medical students' L2 writing scores and intrinsic motivation?

3. Is there a significant relationship between medical students' L2 writing scores and extrinsic motivation?

\section{Method}

\section{Participants}

One hundred EFL medical students (both males and females) participated in this study. They had enrolled in an English academic writing course held in English Language Department of Shiraz University of Medical Sciences. All medical students have to take the academic writing as a compulsory three credit course before graduating from the university. Due to a limitation in our sample size, we selected the studentsof five intact academic writing classes.All classes were taught based on the same writing syllabus.

\section{Procedures and data collection}

The writing class was held twice per week and each session took approximately 90 minutes. The main elements of the schedule were teaching grammar, teaching academic writing such as grammar,paragraph structure, paragraph development, 
opinion paragraph, comparison/contrast paragraph, problem/solution paragraph and essay structure. The course took one semester. To identify the students' strengths and weaknesses, the researchers used ongoing assessments which mainly focused on writing paragraphs on various elements the students learned.

For data collection, the students were asked to write four essays in one semester. The time interval between writing each essay was three weeks.

\section{Instruments}

In this study, we applied the Holistic Scoring Rubric developed by Facione and Facione (2014) to assess the students' writing. It constructs four levels of performance to evaluate the students' writing ranging from strong (4) to significantly weak (1). Inter-rater reliability was applied by researchers to make objective judgment in their scoring.

Moreover, we administered a questionnaire to classify the students' extrinsic/intrinsic motivation. Itwas a five-point Likert-scale motivation questionnaire adopted from Laine (1987); it included 31 items in two main sections (i.e. extrinsic and intrinsic motivation). The reliability of the questionnaire was measured through test-retest by Fazel (2002). ts correlation coefficient was 0.80 which showed a positive correlation between the test items. In this study, to remove the ambiguity of the items and enhance the validity, we used the backtranslation method to translate it into the Persian language. To do so, first, the questionnaire was translated into Persian. Then, the Persian version of the questionnaire was again translated into English without referring to the original text. Finally, the two English versions of the questionnaires were compared with one another by two experts in translation. They paid attention not only to the word by word translation of the text but alsothe underlying concepts that the items were intended to measure. Then, to remove the ambiguity in each item, we did apilot study and the questionnaire was given to 30 university students who did not attend in the main study.

\section{Data analysis and results}

All students' manuscripts $(n=200)$ were scored by there searchers who had taught academic writing for more than three years. First, coding procedures were applied to examine the agreement between the raters. To do so, each researcher tried to mark the students' writing based on the Holistic Scoring Rubric individually.Since the inter-rater reliability was low in the first round $(0.50)$, the researchers tried to enhance their agreement by consulting about discrepancies until the degree of agreement between them reached 0.78 . 
Furthermore, to investigate if there is a significant difference between the students' L2 writing scores and their motivation, one-way ANOVA was applied. As shown in Table 1, a significant difference was found between the students' L2 writing scores and their motivation. It means that the students who had intrinsic motivation got higher scores than those with extrinsic motivation.

Table 1.Comparison of the Students' Writing Scores based on Two Types of Motivation

\begin{tabular}{llcccc}
\hline motivation & & df & Mean & F & Sig. \\
\hline extrinsic & Between Groups & 34 & 99.95 & 2.72 & .000 \\
& Within Groups & 63 & 36.78 & & \\
\hline intrinsic & Between Groups & 33 & 166.11 & 2.62 & .001 \\
& Within Groups & 62 & 63.37 & & \\
& Total & 95 & & & \\
\hline
\end{tabular}

Moreover, to investigate if there is a significant relationship between the medical students' writing scores and intrinsic motivation, Pearson Correlation was run. A significant relationship was found between their writing scores and intrinsic motivation (see Table 2).

Table 2. Correlation between the Students' Writing Scores and Intrinsic Motivation

\begin{tabular}{cllc}
\hline Motivation & & \multicolumn{1}{c}{ Intrinsic } & Writing Score \\
\hline Intrinsic & Pearson Correlation & $0.309 * *$ & 1 \\
& Sig. (2-tailed) & 0.002 & \\
& $\mathrm{~N}$ & 94 & 96
\end{tabular}

Note: $* *$. Correlation is significant at the 0.01 level (2-tailed)

Finally, we ran Pearson Correlation to investigate if there is a significant relationship between the medical students' writing scores and extrinsic motivation.No significant relationship was found between the medical students' writing scores and extrinsic motivation (see Table 3). 
Table 3.Correlation between the Students' Writing Scores and Extrinsic Motivation

\begin{tabular}{cllc}
\hline Motivation & & Extrinsic & Writing Score \\
\hline Extrinsic & Pearson Correlation & 0.17 & 1 \\
& Sig. (2-tailed) & 0.11 & \\
& $\mathrm{~N}$ & 96 & 98 \\
\hline
\end{tabular}

\section{Discussion}

This study was an attempt to investigate the relationship between intrinsic/extrinsic motivation and medical students' L2 writing.We found that the students' motivation has a positive effect on their writing. This finding is in accordance with Fazel and Ahmadi's (2011) study who found a significant relationship between instrumental (extrinsic)/integrative (intrinsic) motivation and writing proficiency among Iranian IELTS candidates.

Moreover, a significant difference between the students' L2 writing scores and their motivation confirms the results of previous research indicating that motivation is essential in the second language learning and teaching. This finding can support other researchers' ideas that various types of motivations such as integrative and instrumental can enhance the students' learning (Moiinvaziri, 2008). Also, motivation is not only an essential element of successful language acquisition but also a dynamic process subject to continuous changes in the students' learning (Do“rnyei, 2001). Our findings are also inconsistent with those of other studies that showed a significant relationship between the students' level of English language proficiency and their motivation (Bagherzadeh \& Azizi, 2012; Langroudi \& Amiri, 2013).This finding may imply that the learner's motivation plays a significant role in determining how students engage in writing activities, what kind of writing tasks they handle, and how much attempt and attention they run through the various phases of the writing process (Bruning \& Horn, 2000).

In this study, a significant relationship was found between the medical students' writing scores and their intrinsic motivation. The results are consistent with those of Gardner and Lambert's (1972) who found that students with integrative motivation (intrinsic motivation) were more successful in learning than those with instrumental motivation (extrinsic motivation).Contrary to Gardner and Lambert's expectations and also in contradiction to our findings, Lukmani (1972) argues that although instrumental and integrative motivation are related to the learners' achievement, the former is more highly correlated with the students' achievement in learning English than the latter. 
Another important finding was that intrinsic motivation affects the students' writing scores more than extrinsic one. Our finding contradicted the results reported by Burstall (1975) who argued that both integrative and instrumental motivation had the same effect on the students' success in language learning. A possible explanation for this finding is thatmedical students who took part in this study were more motivated to do their homework out of their own interest than thinking of getting good marks. This finding does not support the previous research indicating that achieving good grades in examinations could greatly influence the students' writing (Fan, 1999).

Another remarkable finding was that the students figured out the value of writing and considered writing task as doing something inherently exciting or pleasant. This finding is inconsistent with other studies showing that the students' motivation in learning English has been basically driven by extrinsic factors such as vocational and socioeconomic (Bolton \& Luke,1999; Lin (1996) or studying abroad(Fan, 1999; Lin \& Detaramani, 1998; Hoosain, 2005; Lo \& Hyland, 2007).

\section{Conclusion}

Limited work has been done to determine the relationship between the students' motivation and their L2 writing skill. The present research found that the students' motivationis essential in improving their L2 writing skill. Comparing the students' intrinsic and extrinsic motivation, we found that students with intrinsic motivation were more successful than those with extrinsic motivation in L2 writing.

The results of this study can give teachers an in-depth understanding of motivation as a key factor which can improve students' writing. In fact, identifying the relationship between students' motivation and L2 writing can assist teachers in fostering positive and realistic beliefs to maximize their teaching. The results can also help teachers in general and Iranian EFL teachers in particular to be more efficient in their career. They may help EFL students deal with L2 writing with an awareness of motivation in their education.

In this study, we investigated the relationship between students' motivation and their L2 writing skills; investigating the relationship between the students' motivation and learning other skills such as reading, speaking and reading is strongly recommended. Next, this study was conducted on the students of only one university; the result may threaten the external validity and also restrict the generalizability of the findings to the whole population. What is required is another study with a larger population. Next, in this study, we did not consider the impact 
of culture on students' L2 writing. Cross-cultural studies on the relationship between students' motivation and their L2 writing skill are suggested. Last but not least, further work needs to be done to examine if other variables such as students' age, sex, language proficiency and the length of exposure to the language may affect students' motivations in L2 writing.

Acknowledgments: This research program was supported by the grant number 9301-10-8785 from Shiraz University of Medical Sciences Research Council. We would like to thank our colleagues and students for their collaboration in collecting the data.

\section{References and notes:}

Arefi, M. (1997). The relationship between first and second language writing skills for Iranian students in Sydney: An application of the Interdependence Hypothesis. Unpublished Doctoral Dissertation, Nepean, University of Western Sydney. Retrieved from http://www.Irandoc.ac.ir

Ayele, Z. A. (2014). Effects of training in the learning strategies of writing in improving students ${ }^{e e}$ writing skills. International Journal of Research, 1(4), 54-59.

Bagherzadeh, H. \& Azizi, Z. (2012). Learners' beliefs about English language learning: examining the impact of English proficiency level on the motivation of students among non-English major EFL students, Theory and Practice in Language Studies 2(10), 2096-2102.

Bolton, K., \& Luke, K. (1999). Language and society in Hong Kong: The social survey of languages in the 80s. Retrieved from http://www.ssrc.hku.hk/files/language_2/(1999)_The_Social_Survey_of_Languag e_in_the_1980s.pdf

Brown, H. D. (2001) Teaching by principles: An interactive approach to language pedagogy (second edition). New York: Longman.

Bruning, R., \& Horn, C. (2000). Developing motivation to write. Educational Psychologist 35(1), 25-37.

Burstall, C. (1975). Factors effecting foreign language learning: A consideration of some relevant research findings. Language Teaching and Linguistics Abstracts8, 5-125.

Coffin, C., Curry, M. J., Goodman, S., Hewings, A., Lillis, T. M., \& Swann, J. (2003). Teaching academic writing: A toolkit for higher education. New York:NY.

Dörnyei, Z. (2001). Teaching and researching motivation. Harlow: Longman.

Facione, P. A., Facione, N. C. (2014). The holistic critical thinking scoring rubric: A tool for developing and evaluating critical thinking. Retrieved from http://www.insightassessment.com/pdf_files/Rubric\%20HCTSR.pdf

Fan, M. (1999). An investigation into the beliefs and strategies of Hong Kong students in the learning of English. Education Journal, 27(2), 65-81.

Fazel, I., \& Ahmadi, A. (2011). On the relationship between writing proficiency and instrumental/integrative motivation among Iranian IELTS candidates. Theory and Practice I Language Studies, 1(7),747-757. 
Gardner, R. C., \&Lambert, W. E. (1972). Attitudes and motivation in second language learning. Rowley, MA: Newbury House.

Graham, S., Harris, K. R., \& Mason, L. (2005). Improving the writing performance, knowledge, and self-efficacy of struggling young writers: The effects of selfregulated strategy development. Contemporary Educational Psychology, 30(2), 207-241.

Hassani, H. (2005). The relationship between intrinsic and extrinsic motivation and Iranian EFL Students' gender, level of university instruction, and the EFL proficiency. Unpublished M.A. thesis. Shiraz University: Iran.

Hoosain, R. (2005). To be biliterate and trilingual in the Hong Kong Special Administrative Region. In R. Hoosain \& F. Salili (Eds.), Language in Multicultural Education (pp. 255-272). Greenwich, CT: Information Age Publishing.

Kim, Y. H. (2011). Diagnosing EAP writing ability using the Reduced Reparameterized Unified, Language Writing 7(1), 113-131.

Knoch, U. (2009). Diagnostic assessment of writing: The development and validation of a rating scale. Frankfurt: Peter Lang.

Kormos, J. and Dornyei, Z. (2004). The interaction of linguistic and motivational variables in second language task performance. Zeitschrift fur Interkulturellen Fremd sprachenunterricht, retrieved from http://www. ualberta.ca/ german/ejournal/kormos2.htm], 9.19

Laine, J. E. (1987). Affective factors in foreign language learning and teaching. Cross Language Studies. Jyvaskyla: Jyvaskyla University.

Langroudi, J., Amiri,N. (2013). On the relationship among language learning attitude academic motivation and language proficiency of Iranian EFL learners. Iranian EFL Journal,9(2).22-40.

Lin, A. M. Y. (1996). Doing-English-lessons in secondary schools in Hong Kong: A sociocultural and discourse analytic study. Unpublished doctoral dissertation. University of Toronto, Ont.

Lin, A., \& Detaramani, C. (1998). By Carrot and by Rod: Extrinsic motivation and English attainment of tertiary students in Hong Kong (pp. 3-40). In M. Pennington (Ed.), Language in Hong Kong at century's end. Hong Kong: Hong Kong University Press.

Lo, J., \& Hyland, F. (2007). Enhancing students' engagement and motivation in writing: The case of primary students in Hong Kong. Journal of Second Language Writing, 16(4), 219-237.

Lukmani, Y. M. (1972). Motivation to learn and language proficiency. Language Learning, 22(2), 261-273.

Manchón, R. M. (2011). Writing to learn the language: Issues in theory and research. In R. M. Manchón (Ed.). Learning-to-write and writing-to-learn in an additional language (pp.61-84). Amsterdam: John Benjamins.

Moiinvaziri, M. (2008). Motivational orientation in English language learning: A study of Iranian undergraduate students. Global practices of language teaching. Proceedings of International Online Language Conference (IOLC). Universal publishers (pp.126-135).Florida: US.

Nunan, D. (2001). Second language teaching and learning, Heinle and Heinle publications.

Oxford, R., \& Shearin, J. (1994). Language learning motivation: Expanding the theoretical framework. Modern Language Journal, 78(1), 12-28. 
Ryan, R. M., Deci, E.L. (2000). Intrinsic and Extrinsic Motivations: Classic Definitions and New Directions. Contemporary Educational Psychology, 25(1), 54-67.

Salimi, M. R. (2000). Affective factors $n$ learning English: A study of the filters. Unpublished Master thesis. Shiraz University: Iran.

Scarcella, R. C., \& Oxford, R. L. (1992). The tapestry of language learning: The individual in the communicative classroom. Boston: Heinle \& Heinle Publishers.

Tan, B. H. (2011). Innovative writing centers and online writing labs outside North America. Asian EFL Journal, 13(2), 391-418. Retrieved from http://www.asianefl-journal.com/PDF/June_2011.pdf

Vaezi, Z. (2008). Language learning motivation among Iranian undergraduate students. World Applied Sciences Journal, 5 (1), 54-61.

Zia Houseini, S. M., \& Derakhshan, K. (2006). Transfer of first language of foreign language writing: A contrastive rhetoric study of English and Farsi. Quarterly Journal of Humanities Al-Zahra University, 16(58), 75-91.

\title{
Summary
}

\section{The Relationshipbetween Intrinsic/Extrinsic Motivation and Medical Students' L2 Writing}

\author{
Sepideh Nourinezhad \\ Shiraz University of Medical Sciences, Shiraz, Iran
}

\author{
Nasrin Shokrpour \\ Shiraz University of Medical Sciences, Shiraz, Iran
}

\section{Zahra Shahsavar Shiraz University of Medical Sciences, Shiraz, Iran}

Despite the increasing interest in the need to increase the students' learning motivation, there have been few attempts to determine the relationship between the students' motivation and their L2 writing skill.The present study aimed at investigating the effect of extrinsic and intrinsic motivation on Iranian medical students' L2 writing. 100 EFL medical students (both males and females) who had enrolled in an English academic writing course held in English Language Department of Shiraz University of Medical Sciences participated in this study. We used a questionnaire to classify the students' extrinsic/intrinsic motivation. The results showed that the students' motivation has a positive effect on their writing. Moreover, students with intrinsic motivation were more successful than those with extrinsic motivation in L2 writing. This study can provide the instructors with an in-depth understanding of motivation as a key factor which can improve the students' writing. Understanding different types of students' motivation and what promotes their learning skill can assist the teachers in fostering positive and realistic beliefs to maximize their teaching in an educational setting.

Keywords: extrinsic motivation; intrinsic motivation; L2 writing; medical students 